\title{
Feeding of krill around South Georgia. I: A model of feeding activity in relation to depth and time of day
}

\author{
D. J. Morris and C. Ricketts
}

British Antarctic Survey, Natural Environment Research Council, High Cross, Madingley Road, Cambridge CB3 OET, United Kingdom

\begin{abstract}
Antarctic krill Euphausia superba were sampled from 4 depth horizons from a small area off South Georgia every $4 \mathrm{~h}$ for $6 \mathrm{~d}$. Stomach, hepatopancreas and gut fullness of over 9,000 specimens were assessed visually. Plant pigment levels were measured in the stomachs and hepatopancreata of a subsample of the krill: the visual classification distinguished significantly different levels of plant pigment in both organs. Multivariate analysis of the number of krill in each depth, time and feeding category was used to generate a simple model of the relationships between stomach, hepatopancreas and gut fullness and to investigate how they varied with both depth and time of day. Both field techniques and analytic procedures represent an improved approach to the problem of understanding the simultaneous effects of environmental and physiological processes on krill feeding. Neither stomach, hepatopancreas nor gut fullness varied with depth, and only stomach fullness showed any significant variation with time of day. This is in contrast to previous studies which have been based upon smaller samples and less rigorous analyses. Although depth distribution of krill is known to vary with time of day, our results suggest that the link between feeding, swarming and vertical migration may be more tenuous than has previously been supposed.
\end{abstract}

\section{INTRODUCTION}

Swarming and vertical migration of Antarctic krill Euphausia superba Dana are well established phenomena which are as yet poorly understood. It has been suggested that they may be primarily related to the feeding pattern of the krill (Pavlov, 1969). However, a preliminary study of the feeding behaviour of krill around South Georgia (Morris et al., 1983) found only limited evidence for significant biological changes in gut fullness with depth and time of day while Antezana et al. (1983) have shown that feeding occurs both within and outside swarms. Morris et al. (1983) highlighted the need for intensive sampling of a patch of krill in a relatively constant oceanographic environment to elucidate any subtle changes in feeding behaviour which may occur with swarming and vertical migration.

In this study, which is part of an integrated programme for the investigation of Euphausia superba (Bonner et al., 1978), a patch of krill located north-east of South Georgia was sampled in 4 depth horizons, 6 times a day for 6 consecutive days. The data have been used to generate a simple model of the interactions between food in the different parts of the digestive system and to investigate how feeding activity varies in relation to both depth and time of day.

\section{MATERIALS AND METHODS}

A patch of krill located approximately 20 nautical miles north-east of South Georgia $\left(53^{\circ} 55^{\prime} \mathrm{S}, 36^{\circ} 14^{\prime} \mathrm{W}\right.$, max water depth $=220 \mathrm{~m}$ ) was selected for study following an acoustic and oceanographic survey. A $27 \times 27$ nautical mile area containing this patch was intensively surveyed immediately before and after the study to determine changes in the oceanographic parameters and structure of the patch.

Sampling was concentrated within a small area (approximately 3 nautical miles $\times 1$ nautical mile) within the patch. Each sampling period was preceded by a vertical profile of salinity and temperature and by a horizontal and vertical acoustic profile (Simrad EKS 
120) of the haul track. The krill were sampled using a multiple rectangular midwater trawl of mouth area $8 \mathrm{~m}^{2}$ (Roe and Shale, 1979) opening and closing under acoustic command deployed from the stern of the RRS 'John Biscoe' and a $1 \mathrm{~m}^{2}$ frame net deployed at the surface from the foredeck.

For each sampling period the multiple net was deployed to $150 \mathrm{~m}$ depth, the first net opened and hauled over $20 \mathrm{~min}$ to a depth of $100 \mathrm{~m}$. The first net was than closed and the second net opened. This was then hauled for $20 \mathrm{~min}$ to approximately $10 \mathrm{~m}$ below the thermocline and closed. The third net was then opened, hauled rapidly through the thermocline (50 to $70 \mathrm{~m}$ ) and fished for $20 \mathrm{~min}$ up to a depth of $10 \mathrm{~m}$. The net was then closed and hauled aboard. During deployment of the multiple net a surface sample $(0$ to $3 \mathrm{~m}$ ) was obtained from the foredeck with a 5 min haul. All samples were obtained at a towing speed of approximately $2.5 \mathrm{kt}$. The sampling regime was repeated every $4 \mathrm{~h}$ for $6 \mathrm{~d}$, from the $2 \mathrm{nd}$ to the 7 th of January, 1982.

\section{Classification of feeding states}

Length (anterior edge of eye to tip of telson), maturity stage and sex (where appropriate) of up to $100 \mathrm{krill}$ from each net were assessed (Makarov and Denys, 1980). Stomach, hepatopancreas, mid-gut, and hindgut fullness for each krill were visually classified as follows:

Stomach: $0,1,2$ on the basis of increasing colour intensity (green) and fullness

Hepatopancreas: 0, 1, 2 on the basis of increasing colour intensity (green)

Mid-gut: $0,1,2$ on the basis of the number of thoracic body segments with the gut containing faecal material

Hind-gut: $0,1, \ldots 6$ on the basis of the number of abdominal body segments with the gut containing faecal material.

A subsample of krill was collected at random from the 100 analysed from each net and the stomach and hepatopancreas dissected out. Total plant pigments (chlorophyll a plus phaeophytin) were extracted into acetone and measured fluorometrically (Strickland and Parsons, 1972).

\section{Data analysis}

Each krill sampled could be classified by the depth stratum from which it came, the time of day it was caught, and stomach, hepatopancreas, mid-gut and hind-gut fullness. Because there was likely to be a major effect of each component of the digestive system upon the others (e.g. stomach fullness may influence hepatopancreas fullness), the single classifications of stomach, hepatopancreas, mid-gut and hind-gut fullness were not analysed separately with respect to depth and time of day. Rather a 6-way contingency table classified by depth (4 levels), time of day ( 6 levels), stomach fullness (3 levels), hepatopancreas fullness (3 levels), mid-gut fullness (3 levels) and hindgut fullness ( 7 levels) was constructed. Each of the 9,421 krill analysed was allocated to the appropriate cell of the table. The raw data for analysis were, therefore, the number of krill falling into each of the 4,536 categories.

The analysis of the contingency table followed the approach of Bishop et al. (1975). The data were represented by a log-linear model involving parameters which estimate differences between numbers of animals in each class for each variable (main effects, e.g. stomach fullness) and parameters which estimate the interdependences of 2 or more variables (interactions, e.g. time/depth). A hierarchical series of models were fitted to the data and maximum likelihood estimates of these parameters obtained using the iterative proportional fitting algorithm in GENSTAT (Alvey et al., 1980) on a Honeywell 66/DPS-300 computer. Threeway and higher interactions (e.g. time/depth/stomach/ hepatopancreas) were not considered to be of biological importance: indeed, they involved 4,356 of the total of 4,536 possible parameters but explained only $9 \%$ of the variation of the data. The main effects and 2-way interactions involved only 180 parameters and explained the remaining $91 \%$ of the variation.

Because of the large amount of data, all effects were likely to be statistically if not biologically significant (Benedetti and Brown, 1980). Thus a significance level was chosen of $1 \%$ of the deviance (goodness of fit statistic; Nelder, 1974) of the model including only the main effects of depth and time and their interaction: this model allows only for variation in sample size for each depth/time category. A simplified model of krill feeding was established by eliminating non-significant 2-way interactions.

\section{RESULTS}

\section{Homogeneity of the population}

Length-frequency analysis of the samples of krill showed that the population could be considered homogeneous over the $6 \mathrm{~d}$ sampling period (see also Clarke and Morris, 1983). In addition, local currents, chlorophyll levels and salinity/temperature diagrams along the haul track showed little variation within the 
Table 1. Euphausia superba. Number of specimens analysed for each time/depth block (bar: darkness)

\begin{tabular}{|c|c|c|c|c|c|c|c|}
\hline \multirow[t]{2}{*}{ Depth range (m) } & \multicolumn{6}{|c|}{ Time range $(h$, local $)$} & \multirow[b]{2}{*}{$\begin{array}{l}\text { Total number } \\
\text { of krill sampled }\end{array}$} \\
\hline & $20-24$ & $24-04$ & $04-08$ & $08-12$ & $12-16$ & $16-20$ & \\
\hline Surface $(0-3)$ & 500 & 600 & 48 & 1 & 12 & 36 & 1197 \\
\hline Above thermocline $(10-50)$ & 487 & 600 & 416 & 309 & 485 & 303 & 2600 \\
\hline Below thermocline $(70-100)$ & 421 & 600 & 509 & 400 & 465 & 367 & 2762 \\
\hline Below $100(100-150)$ & 485 & 600 & 502 & 343 & 431 & 501 & 2862 \\
\hline Total number of krill sampled & 1893 & 2400 & 1475 & 1053 & 1393 & 1207 & 9421 \\
\hline
\end{tabular}

study period: this is discussed fully in Morris et al. (in prep.). The data for each day of the study period were, therefore, combined into the appropriate depth, time and feeding categories.

The number of krill analysed for each time/depth category is shown in Table 1 . The maximum number sampled was 600: the low numbers found at the surface during the daylight hours reflected the vertical migration of krill off South Georgia (Everson, 1982). All models of krill feeding fitted to the data take this variation in sample size into account by including the main effects and interaction of depth and time.

\section{Classification of stomach and hepatopancreas fullness}

Levels of plant pigments in a subsample of krill of each visual classification and lengths of animals were log-transformed to normalize the distribution of plant pigment levels and linearize the relationship between plant pigment and length of krill. There was a clear increase in plant pigment with increase in class number (Table 2) for both stomach (ANOVA, F[2;115] $=116, \quad \mathrm{P} \ll 0.001$ ) and hepatopancreas (ANOVA, $\mathrm{F}[2 ; 115]=84, \mathrm{P} \ll 0.001)$. However, there was considerable variation in pigment levels within each class. This could be partly explained by the size variation of the krill for both stomach classes (analysis of covariance, $F[1 ; 115]=26, P \ll 0.001)$ and hepatopan-

Table 2. Euphausia superba. Levels of plant pigment (ng chlorophyll a plus phaeophytin) found in stomach and hepatopancreas. Means of log-transformed data adjusted for regression on log-length. Sample size shown in brackets

\begin{tabular}{|c|c|c|}
\hline Organ & Stomach & Hepatopancreas \\
\hline \multicolumn{3}{|l|}{ Visual code } \\
\hline 0 & (23) & (28) \\
\hline 1 & $(24)$ & 20.3 \\
\hline 2 & 14.5 & 96.5 \\
\hline $\begin{array}{l}\text { Standard error } \\
\text { of difference } \\
\text { between classes }\end{array}$ & $1.17(119)$ & 1.27 (119) \\
\hline
\end{tabular}

creas classes (analysis of covariance, $F[1 ; 115]=14$, $\mathrm{P}<0.001)$.

\section{Models of krill feeding}

Proportions of krill found in each feeding category, irrespective of depth or time, are shown in Table 3 . The majority (70\%) of the krill had full stomachs (Code 2 ) and part-full hepatopancreata (Code 1), and most of these had faeces present in both the mid-gut and hindgut. Less than $10 \%$ had only part-full stomachs (Code 1) and less than $4 \%$ of the krill examined
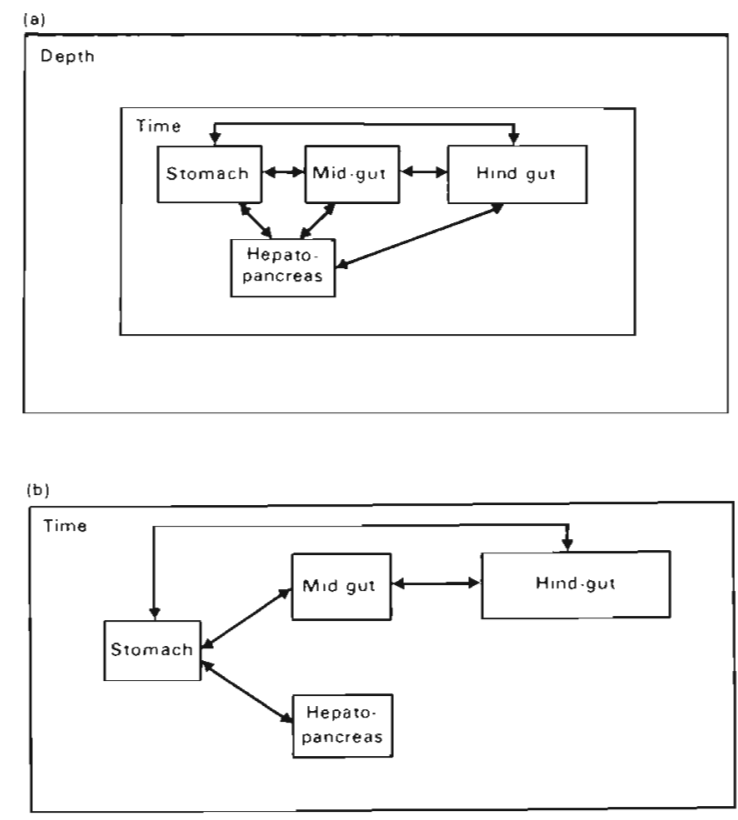

(c)

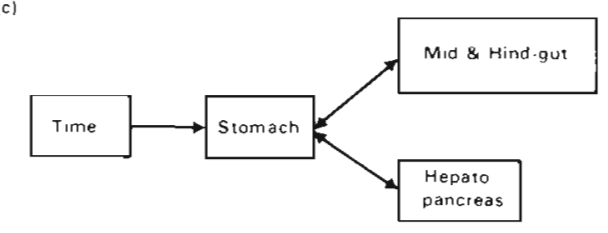

Fig. 1. Euphausia superba. Environmental-animal and intraanimal feeding interactions off South Georgia. (a) Complex model; (b) intermediate model; (c) simple model 
Table 3. Euphausia superba. Percentage of specimens in each feeding category. Data < $0.5 \%$ represented by $(+)$, zero represented by $(\bullet)$

\begin{tabular}{|c|c|c|c|c|c|c|c|c|c|}
\hline \multirow{2}{*}{$\begin{array}{c}\text { Stomach } \\
\text { visual code }\end{array}$} & \multirow{2}{*}{$\begin{array}{c}\text { Hepatopancreas } \\
\text { visual code }\end{array}$} & \multirow{2}{*}{$\begin{array}{l}\text { Mid-gut } \\
\text { fullness }\end{array}$} & \multicolumn{7}{|c|}{ Hind-gut fullness } \\
\hline & & & 0 & 1 & 2 & 3 & 4 & 5 & 6 \\
\hline \multirow[t]{9}{*}{0} & 0 & 0 & 8.0 & + & + & + & . & . & . \\
\hline & & 1 & + & + & - & - & + & - & - \\
\hline & & 2 & + & + & + & . & . & - & • \\
\hline & 1 & 0 & 1.4 & + & - & - & - & - & - \\
\hline & & 1 & + & + & + & - & + & - & - \\
\hline & & 2 & - & + & + & + & - & - & - \\
\hline & 2 & 0 & - & • & • & • & . & • & . \\
\hline & & 1 & . & • & . & - & • & • & . \\
\hline & & 2 & - & . & - & • & • & • & • \\
\hline \multirow[t]{9}{*}{1} & 0 & 0 & 0.9 & + & + & + & + & . & + \\
\hline & & 1 & + & + & + & + & + & + & • \\
\hline & & 2 & + & + & + & + & + & + & + \\
\hline & 1 & 0 & 1.2 & + & + & + & + & + & + \\
\hline & & 1 & + & + & + & + & + & + & - \\
\hline & & 2 & + & 0.5 & + & + & + & + & + \\
\hline & 2 & 0 & - & . & . & + & - & . & • \\
\hline & & 1 & . & + & . & . & + & - & - \\
\hline & & 2 & - & + & - & + & • & . & - \\
\hline \multirow[t]{9}{*}{2} & 0 & 0 & 0.9 & + & + & + & + & + & . \\
\hline & & 1 & 0.7 & + & + & + & + & + & . \\
\hline & & 2 & 0.8 & 0.8 & 0.8 & 0.6 & + & + & + \\
\hline & 1 & 0 & 3.7 & 1.0 & 1.5 & 1.6 & 0.7 & + & + \\
\hline & & 1 & 4.1 & 2.7 & 3.1 & + & + & + & + \\
\hline & & 2 & 4.9 & 7.5 & 10.6 & 9.8 & 6.1 & 2.3 & 0.5 \\
\hline & 2 & 0 & + & + & + & + & + & + & • \\
\hline & & 1 & + & + & + & + & + & + & • \\
\hline & & 2 & + & 0.6 & 0.6 & 0.5 & + & + & + \\
\hline
\end{tabular}

showed full hepatopancreata (Code 2). However, $8 \%$ had their digestive tracts classified as completely empty (stomach $=0$, hepatopancreas $=0$, mid-gut $=0$, hind-gut $=0$ ).

The analysis of the contingency table feeding data started with the assumption that a complex model (Fig. 1a) was appropriate. This model includes interactions between all components of the digestive system and interactions between each component of the digestive system and both depth and time. The successive fitting of hierarchical models allowed the variation in the data to be assigned to each of the sets of main effects and interactions. The breakdown of variation by main effects and interactions is shown in Table 4. Interaction between depth and each component of the digestive system accounted for less than $1 \%$ of the variation, as did the interactions between hepatopancreas and both mid-gut and hind-gut. In the time/animal interactions, the time/stomach interaction accounted for more than $1 \%$ of the deviance. Time/animal interactions were, therefore, investigated in more detail in a simplified model.

The elimination of the non-significant interactions allowed the construction of a simplified model (Fig. 1b) in which time, but not depth, affects the digestive system and where the hepatopancreas is affected only by the level of stomach contents, and not by the other components of the digestive system.

Examination of the fitted parameters of the loglinear model suggested that the classification of the 2 parts of the gut was overelaborate and that functionally they could be combined. Moreover, it seemed that a classification based on only 3 levels would be adequate. The classification of gut fullness was, therefore, condensed to:

0 : mid-gut and hind-gut both 0

1: hind-gut $0-4$ but excluding class 0 above

2: hind-gut 5 or 6

A new contingency table classified by depth, time, stomach, hepatopancreas and gut (mid-gut and hindgut) was constructed: this had only $14 \%$ of the parameters but accounted for $92 \%$ of the deviance of the previous model.

The proportion of krill falling into each of the new feeding categories is shown in Table 5 . With the new classification 3-way and higher order interactions accounted for $4 \%$ of the variation within the data. The complete breakdown of variation by main effects and 
Table 4. Breakdown of deviance of the feeding model with full gut classification. Interactions between variables indicated by a dash (e.g. stomach/hepatopancreas)

\begin{tabular}{|c|c|}
\hline Parameters & $\%$ deviance \\
\hline Main effects & 63.0 \\
\hline $\begin{array}{c}\text { Stomach/hepatopancreas } \\
\text { /mid-gut } \\
\text { /hind-gut }\end{array}$ & 20.4 \\
\hline $\begin{array}{r}\text { Hepatopancreas/mid-gut } \\
\text { /hind-gut }\end{array}$ & 0.5 \\
\hline Mid-gut/hind-gut & 2.1 \\
\hline $\begin{array}{l}\text { Time/stomach } \\
\text { /hepatopancreas } \\
\text { /mid-gut } \\
\text { /hind-gut }\end{array}$ & 3.5 \\
\hline $\begin{array}{c}\text { Depth/stomach } \\
\text { /hepatopancreas } \\
\text { /mid-gut } \\
\text { /hind-gut }\end{array}$ & 1.5 \\
\hline 3-way and higher order interactions & 9.2 \\
\hline
\end{tabular}

interactions is shown in Table 6. The interactions between depth and all components of the digestive system accounted for $<1 \%$ of the variation as did the interactions between hepatopancreas and gut. The only significant interaction of time was with stomach fullness $(1.7 \%)$ : there was no significant interaction between time and either hepatopancreas or gut fullness. Interactions between stomach and hepatopancreas fullness and stomach and gut fullness accounted for $7.4 \%$ and $10.2 \%$ of the variation, respectively.

The removal of the non-significant interactions from the new model indicate a simple model for the feeding of krill around South Georgia (Fig. 1c). Stomach fullness changes with time of day and interacts with both hepatopancreas and gut fullness. Hepatopancreas fullness does not interact with gut fullness. Neither hepatopancreas nor gut fullness are affected directly by time of day, and depth has no significant effect on the fullness of any component of the digestive system.

\section{DISCUSSION}

Knowledge of the factors affecting feeding of krill in the field is important in understanding relationships with vertical migration, swarming and oceanic environment. Pavlov (1969) proposed that feeding, vertical migration and swarming were closely linked. That model, and other studies of the feeding behaviour of Euphausia superba have been based on either limited field sampling (Pavlov, 1969; Gubsch, 1979; Kalinowski and Witek, 1980; Morris et al., 1983) or
Table 5. Euphausia superba. Percentage of specimens in each feeding category using the condensed gut classification. Data $<0.5 \%$ represented by $(+)$, zero represented by (.)

\begin{tabular}{|ccccc|}
\hline $\begin{array}{c}\text { Stomach } \\
\text { visual code }\end{array}$ & $\begin{array}{c}\text { Hepato- } \\
\text { pancreas } \\
\text { visual code }\end{array}$ & 0 & \multicolumn{4}{c|}{$\begin{array}{c}\text { Gut } \text { (mid-gut + hind-gut) } \\
\text { fullness code }\end{array}$} \\
\hline 0 & 0 & 8.0 & + &. \\
& 1 & 1.5 & + & $\cdot$ \\
1 & 2 & $\cdot$ & $\cdot$ & $\cdot$ \\
& 0 & 1.0 & 2.0 & + \\
& 1 & 1.2 & 4.6 & + \\
2 & 2 & $\cdot$ & + & $\cdot$ \\
& 0 & 1.0 & 5.7 & + \\
& 1 & 3.9 & 62.0 & 4.3 \\
& 2 & + & 3.2 & + \\
\hline
\end{tabular}

Table 6. Euphausia superba. Breakdown of deviance of the feeding model with condensed gut classification. Interactions between variables indicated by a dash (e.g. stomach/ hepatopancreas)

\begin{tabular}{|cc|}
\hline \multicolumn{1}{|c|}{ Parameters } & \% deviance \\
\hline Main effects & 74.7 \\
Stomach/hepatopancreas & 7.4 \\
/gut & 10.2 \\
Hepatopancreas/gut & 0.3 \\
$\begin{array}{c}\text { Time/stomach } \\
\text { /hepatopancreas } \\
\text { /gut }\end{array}$ & 1.7 \\
Depth/stomach & 0.5 \\
/hepatopancreas & \\
3-way and higher & 0.7 \\
\hline
\end{tabular}

extrapolation from laboratory experiments (Antezana et al., 1983; Morris et al., 1983). The available information is contradictory and it is likely that no single model for krill feeding will be applicable over the wide range of oceanic conditions in which krill are found. A previous study (Morris et al., 1983) suggested that off South Georgia, krill feeding was related in some way to both depth and time of day, and hence was possibly associated with aggregation and dispersion of krill swarms, although in a different way from that proposed by Pavlov (1969). In this study we have concentrated on the effects of depth and time of day on feeding, with other environmental factors varying minimally. This intensive field study has provided data on the interactions of feeding, swaming and vertical migration of krill and allowed the construction of a simple model for feeding of krill off South Georgia.

To determine the relative importance of the large 
number of potential feeding states, from empty to completely full, large samples of krill need to be analysed This can effectively be achieved by a simple visual assessment of stomach and hepatopancreas fullness and a count of the number of thoracic and abdominal segments in which the gut contains faecal matter Antezana and Ray (1984) were unable to demonstrate significant differences between measured levels of plant pigment on the basis of visual assessinent. Off South Georgia, Morris et al. (1983) had similar problems which have been resolved in this study by the use of a simple classification designed to cover empty, part full and full stomachs and hepatopancreata. Although there was considerable variation in plant pigment levels within the classes, this simple classification reflects significantly different levels of the plant pigment content of both the stomach and hepatopancreas. The classification of gut fullness used initially (midgut and hind-gut) was found to be cver-elaborate. A more simple classification based on retrospectively assigned categories could be used with no significant loss of information. The use of a simple, 3-level classification - empty, part full, full - for stomach, hepatopancreas and gut provided essentially the same information as more complex categories and, by reducing the number of potential feeding state categories, could greatly simplify both the collection and analysis of the data.

Feeding and digestion involve a number of processes, each of which may affect the others. When examining the effects of the environment, interactions within the animal must also, therefore, be taken into account. Simple analysis of a single variable could confuse ecological effects with physiological processes. Although a multivariate analysis, such as that described here, is both complex and expensive in computer time (fitting the most complex model took $3 \mathrm{~h}$ of central processor time), it allows separation of the external effects on the animal from the internal effects. Thus, we have demonstrated that, while time of day affects stomach fullness, and stomach fullness affects gut fullness, there does not appear to be a direct effect of time of day on gut fullness. This is in contrast to the conclusions of Morris et al. (1983) who found a minimum in gut fullness after dawn. To what extent this reflected a different feeding process off South Georgia at that time, an inadequate sampling regime, or too simplistic an analysis is unknown.

As a result of a comprehensive and intensive sampling strategy this study has been able to generate a simple, physiologically realistic model of krill feeding in relation to both depth and time of day. Off South Georgia under the prevalent oceanographic conditions, the digestive system of krill can be regarded as 3 functionally distinct units: stomach, hepatopancreas and combined mid- and hind-gut. Stomach fullness (amount of ingested food) affects both hepatopancreas and gut fullness. However, the amount of plant pigment in the hepatopancreas (digested food), does not affect the amount of faecal material in the gut. This suggests that cell breakdown occurs primarily in the stomach and food absorption in the hepatopancreas, while non-absorbable material (such as cell walls) moves from the stomach directly into the gut: this is consistent with the anatomy of krill (Mauchline and Fisher, 1969).

The variation of stomach fullness with time of day resulted in more full stomachs being observed during and immediately after the hours of darkness. This probably reflects an increase in the level of filtration activity which affects stomach fullness directly. However, hepatopancreas and gut fullness represent the cumulative effects of stomach fullness and this damps out any variation with time. Neither stomach, hepatopancreas nor gut fullness varied with depth. This contrasts strongly with previous models of feeding. The distinction of the subtle effects of time of day, depth and intra-animal interactions indicate a complex and varied feeding behaviour which may not be as strongly linked to vertical migration as previous data have indicated.

Acknowledgements. We wish to thank officers and crew of RRS 'John Biscoe' and all members of the OBP team for assistance with field sampling, and Andrew Clarke and John Croxall for helpful comments on the manuscript.

\section{LITERATURE CITED}

Alvey, N. G., Banfield, C. F., Baxter, R. I., Gower, J. C. Krzanowski, W. J., Lane, P. W., Nelder, J. A., Payne, R. W. Phelps, K. M., Rogers, C. E., Ross, G. J. S., Simpson, H. R., Todd, A. D., Wedderburn, R. W. M., Wilkinson, G. N (1980). GENSTAT: a general statistical program. Rothamsted Experimental Station, U.K.

Antezana, T., Ray, K. (1984). Feeding of Euphausia superba in a swarm North of Elephant Island. J. Crust. Biol. Sp. No.

Antezana, T., Ray, K., Melo, C. (1983). Trophic behaviour of Euphausia superba Dana in laboratory conditions. Polar Biol. 1: $77-82$

Benedetti, J. K., Brown, M. B. (1980). Strategies for the selection of log-linear models. Biometrics 34: 680-686

Bishop, Y. M. M., Fienberg, S. E., Holland, P. W. (1975). Discrete multivariate analysis. MIT Press, Cambridge, Mass.

Bonner, W. N., Clarke, A., Everson, I., Heywood, R. B. Whitaker, T. M., White, M. G. (1978). Research on krill in relation to Southern Ocean ecosystem by the British Antarctic Survey. ICES C.M. 23: 6

Clarke, A., Morris, D. J. (1983). Towards an energy budget for krill: the physiology and biochemistry of Euphausia superba Dana. Polar Biol. 2: 69-86

Everson, I. (1982). Diurnal variations in mean backscattering strength of an Antarctic krill (Euphausia superba). J. Plankton Res. 4: 155-162 
Gubsch, G. (1979). Investigations on krill Euphausia superba off South Orkneys and South Shetlands in 1979. ICES C.M. L34: 12

Kalinowski, J., Witek, Z. (1980). Diurnal vertical distribution and migration of krill swarms in the Western Antarctic. ICES C.M. L49: 12

Makarov, R. R., Denys, C. J. (1980). Stages of sexual maturity of Euphausia superba. BIOMASS Handbook, No. 11. SCAR, Cambridge

Mauchline, J., Fisher, L. R. (1969). The biology of euphausiids. Academic Press, London

Morris, D. J., Everson, I., Ricketts, C., Ward, P. (in prep.). Feeding of krill around South Georgia. II: Relationships between the environment, vertical distribution and feeding activity

Morris, D. J., Ward, P., Clarke, A. (1983). Some aspects of feeding in the Antarctic krill Euphausia superba. Polar Biol. 2: 21-26

Nelder, J. A. (1974). Log-linear models for contingency tables: a generalisation of classical least squares. Appl. Statist. 23: 323-329

Pavlov, V. Ya. (1969). Pitanie krilya i nekotorye osobennosti ego povedeniya (The feeding of krill and some features of its behaviour). Tr VNIRO 66: 207-222. (MAFF Translation no. NS94)

Roe, H. S. J., Shale, D. M. (1979). A new multiple rectangular midwater trawl (RMT $1+8 \mathrm{M}$ ) and some modifications to the Institute of Oceanographic Sciences' RMT $1 \pm 8$. Mar. Biol. 50: 283-288

Strickland, J. D. H., Parsons, T. R. (1972). A practical handbook of seawater analysis. Fish. Res. Bd Can. 167

This paper was submitted to the editor; it was accepted for printing on November 20,1983 